\title{
In Vivo Effects of IgA and IgG2a Anti-CD3 Isotype Switch Variants
}

\author{
Karine J. Parlevliet, * Ineke J. M. ten Berge, " ${ }^{\star}$ Si-La Yong, ${ }^{\ddagger}$ Janto Surachno, ${ }^{\star}$ Joep M. Wilmink, \\ and Peter Th. A. Schellekens \\ ${ }^{*}$ Renal Transplant Unit and ${ }^{\ddagger}$ Clinical Immunology Unit, Academic Medical Center, University of Amsterdam, 1105 AZ Amsterdam, \\ The Netherlands; and ${ }^{\S}$ Laboratory of Experimental and Clinical Immunology of the University of Amsterdam at \\ the Central Laboratory of the Netherlands Red Cross Blood Transfusion Service, Amsterdam, The Netherlands
}

\begin{abstract}
Side effects after the first administration of OKT3, a murine anti-CD3 monoclonal antibody ( $\mathrm{mAb}$ ) of the IgG2a class, are largely attributed to the release of cytokines as a result of $T$ cell activation caused by interaction with Fc receptors (FcR) on human monocytes. As human monocytes possess FcR for murine IgG2a but not for IgA, it is expected that an anti-CD3 $\mathrm{mAb}$ of the IgA class causes less side-effects than an IgG2a antiCD3 mAb of the same idiotype. To test this hypothesis we treated 20 renal transplant patients prophylactically with either IgG2a or IgA anti-CD3 $\mathrm{mAb}$ in a prospective randomized double-blind study. The patients received $0.5 \mathrm{mg}$ anti-CD3 mAb, either IgA ( T3.A) or IgG2a (T3.G2a), twice daily during 10 d. Rejection incidence after T3.A and T3.G2a was not significantly different. Side effects score after the first administration of $\mathbf{m A b}$ was significantly less after T3.A than after T3.G2a (0.7 vs $2.7, P=0.002$ ). IL-6 and gamma IFN levels increased significantly at $3 \mathrm{~h}$ after T3.G2a, but not after T3.A. The TNF peak level occurring at $1 \mathrm{~h}$ after T3.A was much lower than after T3.G2a. In plasma, complement and neutrophil activation products only increased after T3.G2a and not after T3.A. Both T3.A and T3.G2a resulted in a complete depletion of $\mathrm{CD3}^{+}$cells, but after T3.A, CD3 depletion was of shorter duration than after IgG2a. Finally, in contrast to T3.G2a, T3.A did not affect coagulation and fibrinolysis. In conclusion, an anti-CD3 mAb of the IgA class causes hardly any cytokine release and less side-effects as compared with its IgG2a switch variant. Provided T3.A is sufficiently immunosuppressive, it is superior to OKT3. $(J$. Clin. Invest. 1994. 2519-2525.) Key words: renal transplantation • immunosuppression • monoclonal antibodies $\bullet$ side effects - cytokines
\end{abstract}

\section{Introduction}

OKT3, a murine anti-CD3 monoclonal antibody ( $\mathrm{mAb}$ ) of the IgG2a isotype, is among the first mAbs available for treatment in humans. Over the last years it has proven to be a very powerful immunosuppressive agent in renal transplantation, both for prophylaxis and reversal of acute rejection episodes $(1,2)$. However, its extensive use is hampered by severe side effects, mainly occurring in the first hours after the initial dose and

Address correspondence to P. Th. A. Schellekens, Department of Internal Medicine, F4-222, Academic Medical Center, University of Amsterdam, Meibergdreef 9, 1105 AZ Amsterdam, The Netherlands.

Received for publication 26 July 1993 and in revised form 6 December 1993

J. Clin. Invest.

(c) The American Society for Clinical Investigation, Inc.

0021-9738/94/06/2519/07 \$2.00

Volume 93, June 1994, 2519-2525 consisting of fever, chills, gastro-intestinal symptoms, headache, and occasionally pulmonary edema (3-5).

These side effects have been largely attributed to the release of cytokines as a result of transient activation of $T$ cells and monocytes by OKT3. Indeed, within hours after the first administration of OKT3 elevated levels of interleukin-2 (IL-2), interleukin-6 (IL-6), tumor necrosis factor (TNF)- $\alpha$ and $\gamma$-interferon (IFN) were demonstrated in renal transplant recipients that paralleled clinical symptoms (6-11). Also, anti-TNF significantly reduced anti-CD3-induced morbidity in mice and man $(12,13)$. In vitro, ample evidence has accumulated that $\mathrm{T}$ cell activation by anti-CD3 $\mathrm{mAb}$ depends upon the presence of appropriate $\mathrm{Fc}$ receptors $(\mathrm{FcR})^{1}$ on human monocytes to provic: a matrix to favor cross-linking of CD3/T cell receptor (TCR) complexes (14-20). As human monocytes possess FcR for murine IgG2a but not for IgA, anti-CD3-induced morbidity is supposed to be isotype dependent. Both in chimpanzees and in mice administration of $T$ cell non-activating antiCD3 mAb, e.g., IgA anti-CD3 and anti-CD3 $F\left(a b^{\prime}\right)_{2}$ fragments, resulted in less cytokine release and fewer side effects as compared with the administration of $\mathrm{T}$ cell activating $\mathrm{mAb}$ such as $\operatorname{IgG} 2 \mathrm{a}$ anti-CD3 $(21,22)$. Moreover, the observation in mice and chimpanzees that $\mathrm{T}$ cell non-activating anti-CD3 $\mathrm{mAb}$ and $\mathrm{F}\left(\mathrm{ab}^{\prime}\right)_{2}$ fragments do cause $\mathrm{CD} 3$ depletion and result in a prolongation of allogeneic skin graft survival suggests that adequate immunosuppression can be achieved without $T$ cell activation and thus with little or no side effects.

Previously, our group has demonstrated complement activation and subsequent activation of neutrophil granulocytes in renal transplant patients after the first administration of OKT3, and before the rise in cytokine levels occurred (23). It was concluded that, in addition to $T$ cell activation and cytokine release, activation of complement and neutrophils also contribute to the side effects of OKT3. Furthermore, we provided evidence for a disturbance of the procoagulant-fibrinolytic balance after administration of $5 \mathrm{mg}$ OKT3 (24), although this was not accompanied by an increased incidence of thrombotic complications (25). In contrast, Abramowicz et al. (26) reported an increased incidence of thrombotic complications in renal transplant recipients who received OKT3 induction treatment in a dosage of $10 \mathrm{mg}$ daily.

This study was primarily undertaken to test whether a $T$ cell activating and $\mathrm{T} T$ cell non-activating anti-CD3 mAb differ in the generation of side effects in humans. Parameters of anti$\mathrm{CD} 3 \mathrm{mAb}$ related toxicity such as cytokine release, activation of complement, and neutrophil granulocytes as well as parameters of coagulation and fibrinolysis were tested. For this purpose 20 renal transplant recipients were treated with either

1. Abbreviations used in this paper: $\mathrm{FcR}, \mathrm{Fc}$ receptors; MPNS, methylprednisolone; PAPc, plasmin- $\alpha 2$-antiplasmin; TCR, T cell receptor; tPA, tissue-type plasminogen activator. 
IgG2a or IgA anti-CD3 induction therapy in a prospective double-blind randomized study.

\section{Methods}

The study was approved by the Institutional Research and Ethical Committees of the Academic Medical Center of the University of Amsterdam and written informed consent was obtained from all patients.

Monoclonal antibodies. Anti-CD3 isotype switch variants were isolated at our institute as described before $(27,28)$. They have the same idiotype and are thus reactive with the same epitope on the CD3 molecule, their avidity being approximately ten times higher than OKT3 (29). The hybridomas producing monomeric IgA anti-CD3 (T3.A) and IgG2a anti-CD3 (T3.G2a) were cultured under aseptic conditions in a hollow-fiber culture system (Acusyst, P., Endotronics Inc., Coon Rapids, MN) and purified by Euroclone (Amsterdam). T3.A and T3.G2a had been tested before in chimpanzees for toxicity and effects on T lymphocytes (22).

Patient selection and immunosuppressive protocols. Patients were eligible for this study if they were $>18 \mathrm{yr}$ of age, received their first or second renal graft, did not exhibit strong anti-HLA sensitization (defined as $85 \%$ or more panel reactive antibodies) and had not received prior treatment with murine mAb. From October 1991 to August 1992, 20 renal transplant recipients were enrolled in this study. After randomization patients received either T3.G2a or T3.A induction treatment in a double-blind fashion. The mAb code was not broken until $6 \mathrm{wk}$ after the last patient had finished anti-CD3 treatment. Basic immunosuppression from the day of transplantation and during induction treatment consisted of prednisolone/azathioprine. Azathioprine was given orally in a dosage of $2.5 \mathrm{mg} / \mathrm{kg} / \mathrm{d}$, the first dose was given preoperatively. Prednisolone $50 \mathrm{mg}$ i.v. was given twice daily from the day of transplantation until the start of anti-CD3 induction. To be able to monitor anti-CD3 related side effects, anti-CD3 induction was started at day three or four after transplantation. Based on a 10 -fold increased avidity of T3.A and T3.G2a in vitro as compared with OKT3 (29) and the observed pattern of CD3 depletion in chimpanzees (22), we decided to give anti-CD3 induction in a dosage of $0.5 \mathrm{mg}$ i.v. twice daily for $10 \mathrm{~d}$. Before the first administration of anti-CD3 mAb, overhydration was excluded by means of a chest $x$ ray. $1 \mathrm{~h}$ before the first administration of anti-CD3 mAb $500 \mathrm{mg}$ methylprednisolone (MPNS) was given as a single i.v. bolus, together with $25 \mathrm{mg}$ promethazine orally. During anti-CD3 induction, azathioprine was continued as before, with dose adjustment according to the number of platelets and white blood cells (WBC), together with prednisolone $25 \mathrm{mg} / \mathrm{d}$ orally. 2 $d$ before the end of the anti-CD3 induction course cyclosporine was started $8 \mathrm{mg} / \mathrm{kg}$ orally, divided in two daily dosages, provided creatinine clearance was at least $30 \mathrm{ml} / \mathrm{min}$. Cyclosporine dosage was adjusted so as to result in whole blood through levels of $150-200 \mu \mathrm{g} / \mathrm{l}$. When cyclosporine levels were in the therapeutic range, azathioprine was stopped and prednisolone was tapered to $10 \mathrm{mg}$ daily within $3 \mathrm{wk}$. Anti-CD3 induction was stopped in case of severe life-threatening disease and in case of rejection. Acute rejections were treated with MPNS $500 \mathrm{mg}$ as an i.v. bolus for $6 \mathrm{~d}$.

Rejection episodes. Criteria for acute rejection were an increase $(\geq 30 \%$ ) in serum creatinine, clinical symptoms such as fever, oliguria, and swelling or tenderness of the graft in the absence of hydronephrosis on ultrasonography. Rejection episodes were always confirmed by core biopsy.

Side effects during anti-CD3 induction. Side-effects occurring during the first $6 \mathrm{~h}$ after the administration of anti-CD3 $\mathrm{mAb}$ were expressed in the following way: from zero to three and from 3 to $6 \mathrm{~h}$ after anti-CD3 administration patients were observed and questioned for the presence of $(a)$ fever $>38.5^{\circ} \mathrm{C},(b)$ chills, $(c)$ dyspnea, $(d)$ nausea or vomiting, $(e)$ diarrhea, and $(f)$ headache. Each positive symptom was scored $1+$ when present during one interval, $2+$ when present during both intervals. Thus, the cumulative side effects score ranged from zero to 12. Apart from this, body temperature was taken at least four times daily during the first $2 \mathrm{~d}$ of anti-CD3 induction treatment.

Blood sampling and assays. Venous blood samples were obtained with the use of a dwelling catheter that was inserted in one of the femoral veins $1 \mathrm{~h}$ before the first administration of OKT3. According to the literature $(6-8,23-24)$ time points for determination of cytokines, activated complement factors, neutrophil degranulation products, and parameters of coagulation and fibrinolysis were chosen as to result in an optimal reflection of kinetics. Time points chosen were: immediately before and $15 \mathrm{~min}, 30 \mathrm{~min}, 1,3$, and $6 \mathrm{~h}$ after the first three administrations of anti-CD3 mAb. Plasma aliquots of six T3.Aand six T3.G2a-treated patients were stored at $-70^{\circ} \mathrm{C}$. Plasma TNF- $\alpha$ and $\gamma$-IFN levels were measured with a commercially available ELISA resp. IRMA (Medgenix, Billerica, MA). Plasma levels of IL-6 and complement activation products $\mathrm{C} 3 \mathrm{a}$-desarg and $\mathrm{C} 4 \mathrm{~b} / \mathrm{c}$ were determined as previously described (30-32). Plasma levels of neutrophil degranulation products lactoferrin and elastase- $\alpha_{1}$-antitrypsin (AT) complexes were measured with a RIA (33). Prothrombin activation fragment $\mathrm{F} 1+2$ was determined with a commercially available ELISA (Behringwerke AG, Marburg, Germany). Levels of tissue-type plasminogen activator (tPA) and plasmin- $\alpha 2$-antiplasmin complex (PAPc) were measured as described previously $(24,34)$. The upper limit of values in plasma of 20 healthy controls, defined as mean +2 $\mathrm{SD}$ was $40 \mathrm{pg} / \mathrm{ml}$ (TNF- $\alpha), 13 \mathrm{pg} / \mathrm{ml}$ (IL-6), $1 \mathrm{U} / \mathrm{ml}(\gamma$-IFN), 5 $\mathrm{nmol} / \mathrm{l}$ (C3a-desarg), $55 \mathrm{nmol} / \mathrm{l}(\mathrm{C} 4 \mathrm{~b} / \mathrm{c}), 424 \mathrm{ng} / \mathrm{ml}$ (lactoferrin), $117 \mathrm{ng} / \mathrm{ml}$ (elastase- $\left.\alpha_{1}-\mathrm{AT}\right), 1.1 \mathrm{nmol} / \mathrm{l}(\mathrm{F} 1+2), 10 \mu \mathrm{g} / \mathrm{l}(\mathrm{tPA})$ and 7 $\mathrm{nmol} / \mathrm{l}$ (PAPc).

In all patients blood samples for the determination of lymphocyte subsets were drawn immediately before the first administration of anti$\mathrm{CD} 3 \mathrm{mAb}$ and $15 \mathrm{~min}, 30 \mathrm{~min}, 1,3$, and $6 \mathrm{~h}$ thereafter. In addition, during the first $2 \mathrm{~d}$ lymphocyte subsets were determined every $6 \mathrm{~h}$ and the following days twice daily before each subsequent anti-CD3 administration. On day seven, additional blood samples were taken at $30 \mathrm{~min}$, 1,3 , and $6 \mathrm{~h}$ after anti-CD3 administration. Lymphocyte subsets were determined by direct fluorescence using anti-CD2, anti-CD3, antiCD4, anti-CD8, anti-CD19, and anti-TCR mAb labeled with fluorescein or phycoerythrin (Becton Dickinson, Mountainview, CA). Goat anti-mouse fluorescein-labeled antibodies, at a dilution of 1:40, were used to detect in vivo coating of $T$ cells by anti-CD3. In vitro, using serial dilutions of T3.A and T3.G2a, indirect staining with goat antimouse fluorescein-labeled antibodies yielded similar results. Flow cytometry was performed using a FACSCAN. Plasma levels of T3.A and T3.G2a and antibodies to T3.A and T3.G2a were determined with an ELISA (35).

Statistical analysis. Values are expressed as mean \pm SEM. Statistical analysis was performed using the Mann Whitney test, the Cox/Mantel test, and the Wilcoxon Signed Ranks test. The Wilcoxon Signed Ranks test was performed one-sided because only increases were expected and only peak levels were compared with pre-treatment levels. A probability $(P)$ value $<0.05$ was considered to indicate a significant difference.

\section{Results}

Clinical outcome and side effects. 20 renal transplant recipients were treated in a double-blind fashion with either T3.A or T3.G2a induction treatment. Patient characteristics are summarized in Table I. In the T3.A-treated group eight patients completed the induction course: T3.A treatment was abandoned because of acute rejection (one patient, day seven) and septicaemia (one patient, day four). In the T3.G2a-treated group, seven patients completed the course: T3.G2a treatment was canceled because of acute rejection (two patients, day three, respectively, day five) and acute pulmonary edema followed by cardiac arrest (one patient, day two). Resuscitation was successful. At a minimum follow-up period of $6 \mathrm{mo} 5 / 10$ 
Table I. Characteristics of the Patients

\begin{tabular}{lcc}
\hline & T3.A & T3.G2a \\
\hline $\begin{array}{l}\text { No. of patients } \\
\text { Age (yr) }\end{array}$ & 10 & 10 \\
$\quad$ Mean & 46 & 40 \\
$\quad$ Range & $20-67$ & $18-53$ \\
Sex & & \\
$\quad$ M/F & $8 / 2$ & $6 / 4$ \\
Transplant I/II & $9 / 1$ & $9 / 1$ \\
HLA mismatches (mean) & & \\
AB & 1.0 & 1.4 \\
$\quad$ Dr & 0.1 & 0.4 \\
No. of patients with & & \\
$\quad \geq 5 \%$ panel-reactive & & \\
$\quad$ antibodies & 1 & 3 \\
End-stage renal disease & & 3 \\
$\quad$ Chronic glomerulonephritis & 4 & 3 \\
$\quad$ Urologic/interstitial & 2 & 1 \\
$\quad$ Diabetes mellitus & 0 & 2 \\
Polycystic renal disease & 1 & 1 \\
$\quad$ Other/unknown causes & 3 & \\
\hline
\end{tabular}

patients in the T3.A-treated group suffered from rejection, as compared with 4/10 after T3.G2a (n.s.). Patient survival in either group was $100 \%$, graft survival was $70 \%$ after T3.A and $100 \%$ after T3.G2a treatment (n.s.).

In general, T3.A was tolerated much better than T3.G2a, although the first administration of T3.A was not entirely without side effects: $\sim 1 \mathrm{~h}$ after the first mAb administration $8 / 10$ T3.A-treated patients and 9/10 T3.G2a-treated patients had chills. However, maximal body temperature on the first $2 \mathrm{~d}$ of mAb treatment was $37.4 \pm 0.3^{\circ} \mathrm{C}$ for T3.A treated patients and $38.7 \pm 0.3^{\circ} \mathrm{C}$ after T3.G2a treatment $(P=0.005)$. Cumulative side effects score during first $6 \mathrm{~h}$ after the first mAb administration was 0.7 in T3.A-treated patients and 2.7 after T3.G2a treatment $(P=0.002)$. Subsequent administrations of either mAb caused hardly any discomfort. At a minimum follow-up of $6 \mathrm{mo}$, major infectious complications after resp. T3.A or T3.G2a treatment consisted of CMV disease (one vs. four patients) and septicaemia (one patient in either group).

Cytokines. Results of cytokines are given in Fig. 1. Increases were only noted during the first $6 \mathrm{~h}$ after the first antiCD3 administration. Significantly increased TNF peak levels were reached at $1 \mathrm{~h}$ after the first administration of either $\mathrm{mAb}$. However, TNF peak levels were much higher after administration of T3.G2a $(1143 \pm 157 \mathrm{pg} / \mathrm{ml}, P=0.04)$ than after T3.A $(228 \pm 54 \mathrm{pg} / \mathrm{ml}, P=0.04)$. Elevated IL-6 levels were only demonstrated after administration of T3.G2a, with peak levels being reached at three hours $(65 \pm 33 \mathrm{pg} / \mathrm{ml}$, n.s. $)$. Elevated IFN levels were only demonstrated after administration of T3.G2a, with peak levels being reached at $3 \mathrm{~h}(6.7 \pm 2.5 \mathrm{U} / \mathrm{ml}, P$ $=0.04$ ).

Complement and granulocyte activation products. Plasma levels of complement- and granulocyte activation products are depicted in Fig. 2. Increases were only noted during the first $6 \mathrm{~h}$ of anti-CD3 administration. C3a-desarg levels were only slightly elevated after administration of T3.G2a, with peak lev-
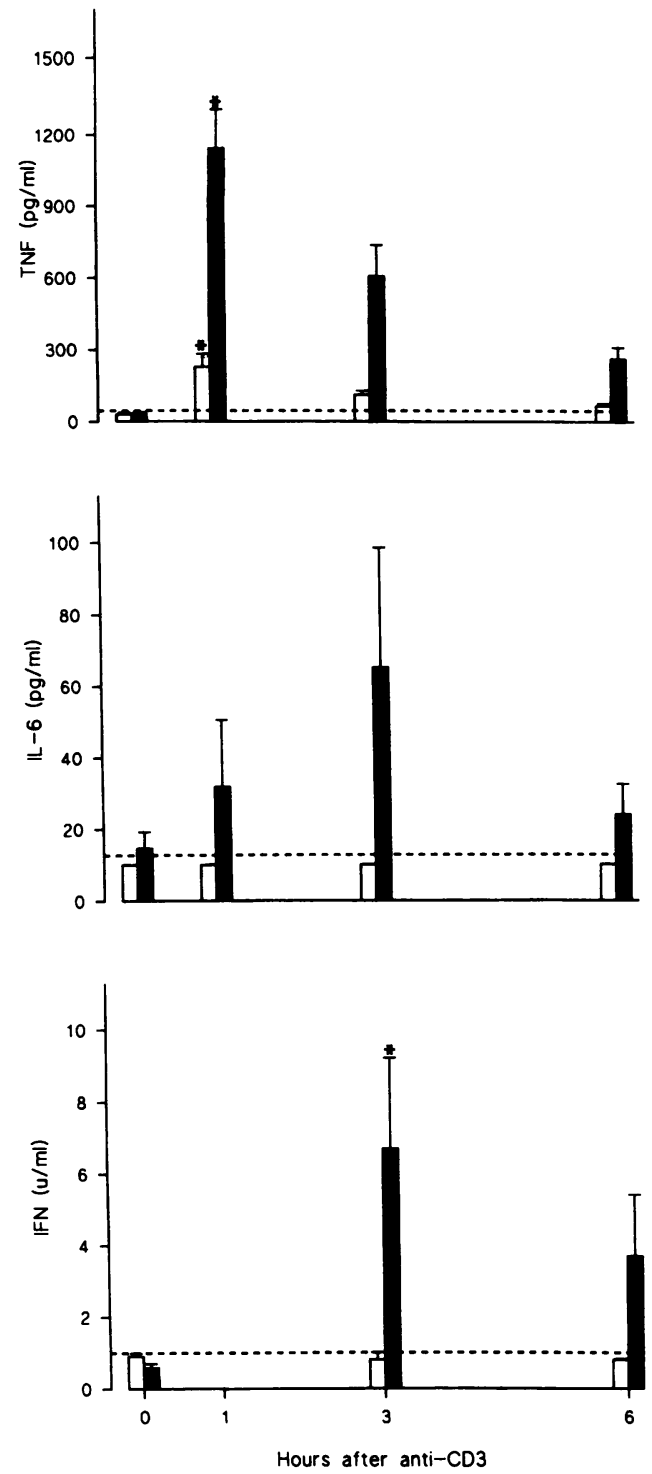

Figure 1. Levels of cytokines (TNF, IL-6, and IFN) during the first 6 $h$ after the first administration of T3.A (open bars) and T3.G2a (closed bars). Results are shown as mean + SEM. Significantly elevated peak levels as compared with pre-treatment levels are indicated by an asterisk. ( $P<0.05$; Wilcoxon Signed Ranks test $)$. Upper limit of normal values is indicated by a dashed line.

els being reached at $6 \mathrm{~h}(7.2 \pm 0.8 \mathrm{nmol} / 1, P=0.04)$. No elevated $\mathrm{C} 4 \mathrm{~b} / \mathrm{c}$ levels were detected after administration of either $\mathrm{mAb}$ at any point of time (data not shown). After administration of T3.G2a there was a slight increase in lactoferrin levels, although peak levels at $3 \mathrm{~h}$ were still in the normal range $(325 \pm 71 \mathrm{ng} / \mathrm{ml}$, n.s.). No elevated lactoferrin levels were detected after administration of T3.A. Pre-treatment levels of elastase- $\alpha_{1}$-AT were slightly elevated and increased signifcantly after administration of T3.G2a with peak levels at $3 \mathrm{~h}$ $(431 \pm 92 \mathrm{ng} / \mathrm{ml}, P=0.04)$, but did not increase after administration of T3.A.

Parameters of coagulation and fibrinolysis. Plasma levels of $\mathrm{F} 1+2$, tPA and PAPc are given in Fig. 3. Increases were only noted during the first $6 \mathrm{~h}$ after the first anti-CD3 administration. Pre-treatment F1 + 2 levels were elevated $(3.0 \pm 0.3 \mathrm{nmol} /$ 

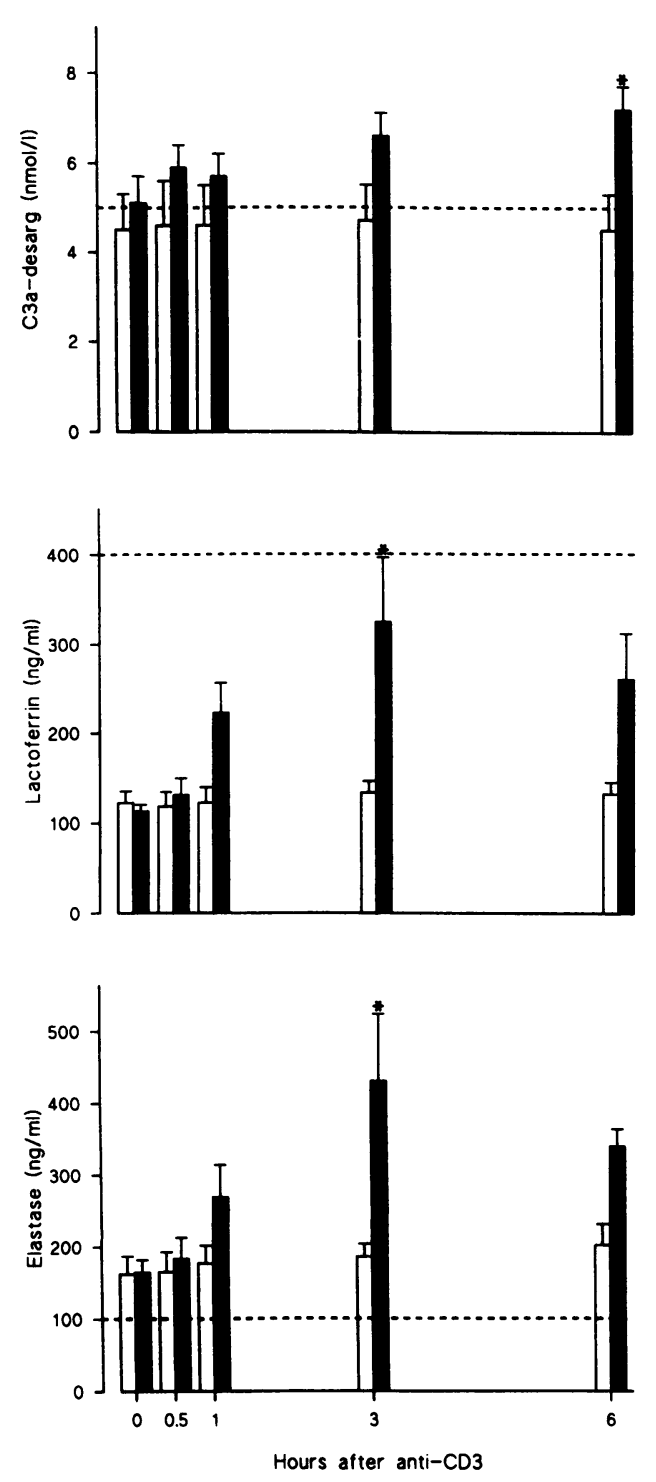

Figure 2. Levels of activated complement factor $(C 3 a)$ and neutrophil degranulation products (lactoferrin and elastase- $\alpha_{1}-\mathrm{AT}$ ) during the first $6 \mathrm{~h}$ after the first administration of T3.A (open bars) and T3.G2a (closed bars). For further explanation see legend to Fig. 1.

1 and $3.6 \pm 0.6 \mathrm{nmol} / 1)$ and increased only slightly after administration of T3.G2a, peak levels being reached at $6 \mathrm{~h}(4.7 \pm 0.9$ nmol/l, n.s.). After administration of T3.G2a both tPA and PAPc levels increased significantly: tPA peak levels were reached at $1 \mathrm{~h}$ and averaged $44 \pm 6.6 \mu \mathrm{g} / 1(P=0.04)$. PAPc peak levels were also reached at $1 \mathrm{~h}$ and averaged $199 \pm 73$ $\mathrm{nmol} / \mathrm{l}(P=0.04)$. After administration of T3.A no increase in $\mathrm{F} 1+2$, t-PA or PAPc levels was observed.

$T$ cell subsets. Both T3.G2a and T3.A resulted in an immediate and profound depletion of CD3 + cells in all patients (Fig. 4): within $30 \mathrm{~min}$ after the first administration of either $\mathrm{mAb}$ the number of $\mathrm{CD} 3+$ cells had decreased to $<10 \%$ of base-line values. However, CD3 depletion after T3.A was of shorter duration than after T3.G2a administration: whereas during the whole period of T3.G2a treatment the number of CD3+ cells remained low as compared with pre-treatment values, T3.A-induced CD3 depletion only lasted for $2 \mathrm{~d}$. From the third day of
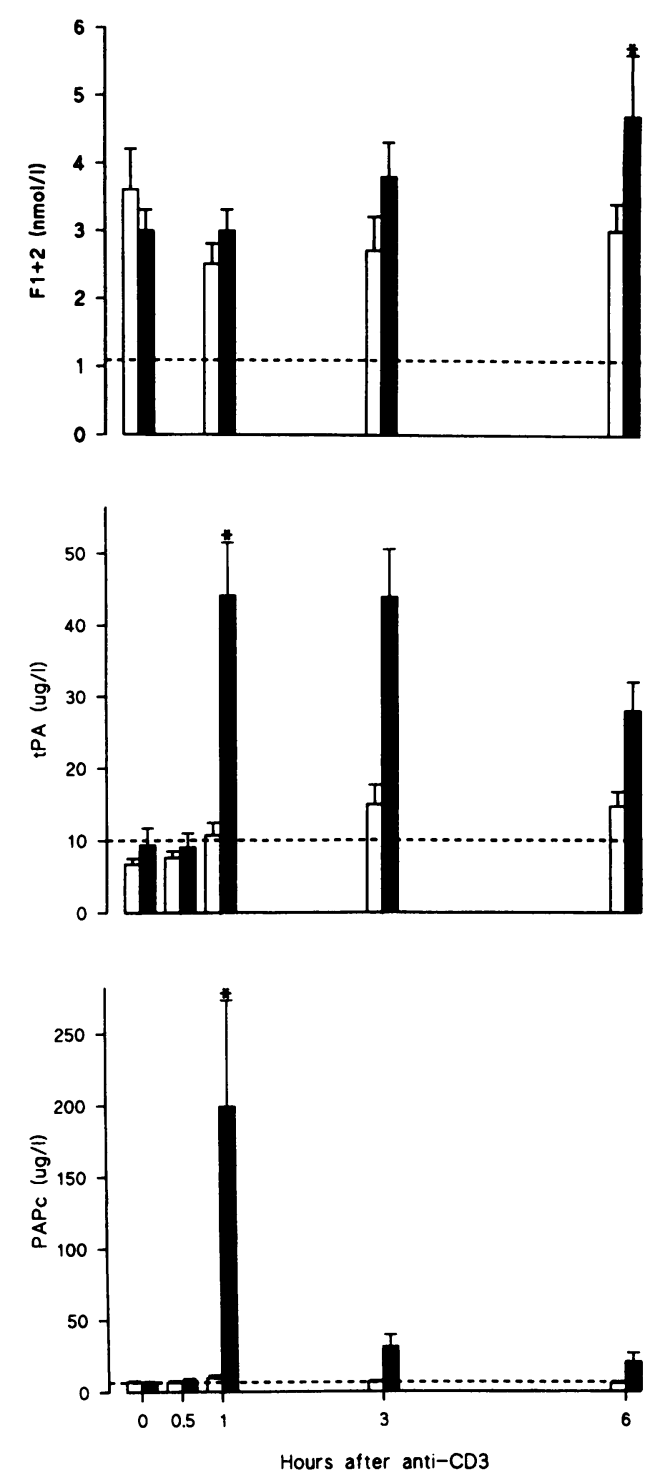

Figure 3. Parameters of coagulation $(F 1+2)$ and fibrinolysis $(t P A$ and $P A P C$ ) the first $6 \mathrm{~h}$ after the first administration of T3.A (open bars) and T3.G2a (closed bars). For further explanation see legend to Fig. 1 .

T3.A administration the number of CD3+ cells, determined twice daily before T3.A administration, approximated baseline values. Nevertheless, frequent measurements on day seven revealed that administration of both $\mathrm{mAb}$ again caused CD3+ cells to disappear transiently from the circulation. Interestingly, at this time no side effects occurred in either group of patients. In addition, compared with pre-treatment values both mAbs caused a decrease in mean channel fluorescence intensity of the recurring CD3+ cells. This decrease was more pronounced during T3.G2a than during T3.A treatment. Mean channel fluorescence intensity of all cells was 510 (on a linear scale) before the institution of anti-CD3 induction therapy, and decreased to 388 (during T3.G2a treatment) or 462 (during T3.A treatment). In spite of the decreased mean channel fluorescence, populations of $\mathrm{CD} 3+$ and $\mathrm{CD} 3-$ cells were clearly distinct. At all time points the number of CD3+ cells equaled the number of $\mathrm{CD} 2+$ cells, the sum of $\mathrm{CD} 4+$ and 

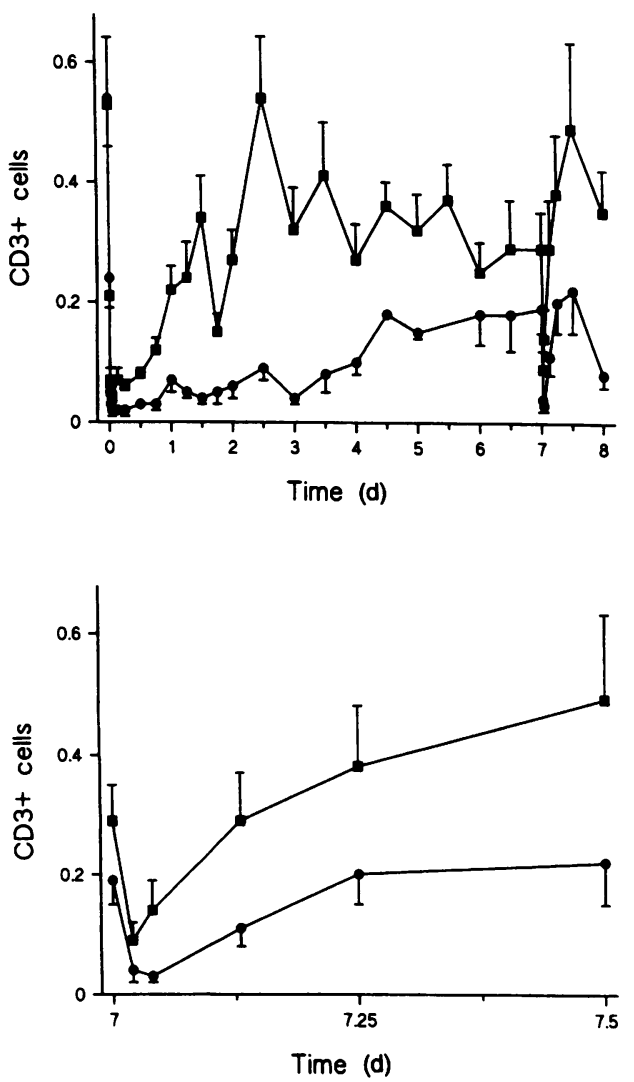

Figure 4. Total number of CD3+ cells during induction treatment with T3.A ( $\bullet$ ) and T3.G2a (•). Results are expressed as mean \pm SEM. Time points given are immediately before the first administration of anti-CD3 $\mathrm{mAb}$ and 15 and $30 \mathrm{~min}, 1,3$, and $6 \mathrm{~h}$ thereafter. Next, during the first $2 \mathrm{~d}$, lymphocyte subsets were determined every $6 \mathrm{~h}$ and the following days this was done twice daily just before anti-CD3 administration. On day seven additional blood samples were drawn at $30 \mathrm{~min}, 1,3$, and $6 \mathrm{~h}$ after anti-CD3 administration (lower panel).

CD8 + cells, and the number of TCR + cells (data not shown). Both during T3.A and during T3.G2a treatment $40-80 \%$ of the $\mathrm{CD} 3+$ cells was coated with murine Ig.

T3.A and T3.G2a levels and antibodies to T3.A and T3.G2a. Murine Ig peak levels obtained $1 \mathrm{~h}$ after the first administration of either $\mathrm{mAb}$ as well as trough levels throughout the whole treatment period were below detection. IgA peak levels, determined on day seven at $1 \mathrm{~h}$ after T3.A administration, averaged $14 \mathrm{ng} / \mathrm{ml}$. At the same time IgG2a peak levels averaged $90 \mathrm{ng} / \mathrm{ml}$. Sera for determination of antibodies to T3.A and T3.G2a were obtained 2 and $4 \mathrm{wk}$ after the last day of anti-CD3 administration. After either T3.A or T3.G2a treatment, $6 / 10$ patients mounted an antibody response. In the majority of patients both isotypic and idiotypic antibodies were demonstrated. However, median antibody titer was 1:1,600 after T3.A and 1:300 after T3.G2a administration.

\section{Discussion}

Our results clearly demonstrate that an IgA anti-CD3 mAb causes significantly less side effects and a markedly decreased cytokine release as compared to an IgG2a anti-CD3 mAb of the same idiotype. Although this study was not primarily designed to test the immunosuppressive properties of T3.A and T3.G2a, rejection incidence after either $\mathrm{mAb}$ did not differ significantly in this small group of patients, but in this respect the statistical power of this study is very low.

Both anti-CD3 mAb under investigation share identical idiotypes (their avidity being $\sim 10$ times higher as compared with OKT3) (29). Therefore the observed difference in side effects and cytokine profile can only be ascribed to the difference in isotype and is in agreement with our observation in vitro that, in contrast to IgG2a anti-CD3, IgA anti-CD3 mAb can not cause $T$ cell activation (27). Moreover, after administration of T3.G2a activation of different cell populations, such as monocytes, macrophages, and natural killer cells, via FcR may also contribute to the early release of TNF, IFN, and IL-6. As pre-treatment with high-dose steroids has been reported to decrease toxicity of IgG2a anti-CD3 mAb in mice and men (6, $8,36-39)$, it is tempting to speculate that omitting pre-treatment with steroids would even have increased the difference in toxicity and cytokine profile of T3.A and T3.G2a. Interesting is the occurrence of chills and TNF release after the first administration of T3.A. This is in agreement with the in vitro TNF production induced by anti-CD3 $\mathrm{F}\left(\mathrm{ab}^{\prime}\right)_{2}$ fragments $(40)$. TNF is generally supposed to be produced by lymphocytes and monocytes $(10,17)$. Administration of TNF as an i.v. bolus to healthy humans results in chills and fever, starting as early as $10 \mathrm{~min}$ after the injection (41). As both mAbs were tested extensively in our laboratory and were found to be free of endotoxin-known to be a trigger for TNF release-it seems very unlikely that contamination with endotoxin is responsible for these events. Perhaps other cells than peripheral blood mononuclear cells (endothelial cells ?) may be an additional source of TNF production.

After administration of T3.A no elevated levels of complement activation or neutrophil degranulation products were detected in plasma. This is in agreement with the general assumption that monomeric murine IgA is a poor activator of complement. After administration of T3.G2a C4b/c levels did not increase at any time point, while a small but significant increase in C3a levels was observed at $6 \mathrm{~h}$. From an earlier study we concluded that side-effects after OKT3 are not only caused by cytokine release but that activation of complement and neutrophil granulocytes are at least as important (23). In agreement with these data, the early rise in neutrophil degranulation products, ascribed to complement activation, did not occur after T3.G2a administration. The late increase in elastase- $\alpha_{1^{-}}$ AT and lactoferrin levels at three hours after T3.G2a administration can be attributed to the strong cytokine response following T3.G2a (42-45).

Both mAbs caused an early and almost complete CD3 depletion, but CD3 depletion after T3.A was of shorter duration than after T3.G2a treatment. These results are in keeping with an earlier report from our group in chimpanzees (22), although in our patients the duration of lymphopenia on the first day of anti-CD3 treatment is also influenced by MPNS pretreatment (46). Remarkably, on day seven both mAbs again induced a rapid but transient $\mathrm{CD} 3$ depletion. We propose that two different mechanisms are responsible for the disappearance of $\mathrm{CD} 3+$ cells after anti-CD3 administration. First, the rather long-lasting $\mathrm{CD} 3$ depletion occurring on the first day of T3.G2a treatment, that is accompanied by severe side effects, is probably mediated by FcR and by adherence to complement 
receptors via complement activation. This mechanism is isotype dependent and is operational only during T3.G2a treatment. However, on day seven, T3.G2a-induced CD3 depletion is of short duration. It is conceivable that after prolonged treatment with T3.G2a FcR blockade is caused by saturation of $\mathrm{FcR}$ in the mononuclear phagocytic system. Interestingly, at day seven, T3.G2a-induced CD3 depletion is not paralleled by side effects, so it seems likely that activation of $\mathrm{T}$ cells and monocytes does not occur at this moment. The latter is also suggestive for FcR blockade. A second mechanism, that is not FcR dependent, may be responsible for the very shortlasting CD3 depletion observed on day one after administration of T3.A and on day seven after the administration of either mAb. We are currently investigating whether margination of $T$ cells to vascular endothelium via upregulation of adhesion molecules plays a role in anti-CD3-induced $\mathrm{T}$ cell depletion.

T3.A and T3.G2a trough levels are extremely low, compared with OKT3 levels, when administered in the same dosage (K. J. Parlevliet, manuscript submitted for publication). The higher avidity of T3.A and T3.G2a compared with OKT3 may explain this. Also, the observation that the T3.A peak level, measured at day seven is much lower than the T3.G2a peak level can be explained by the higher number of circulating CD3+ cells during T3.A treatment. Since CD3+ cells were coated with murine Ig during treatment with either $\mathrm{mAb}$, the decreased mean channel fluorescence intensity of the recurrent CD3 + cells may be caused by blindfolding rather than by modulation (i.e., a decreased number of CD3 molecules per cell) as described in earlier reports on OKT3 treatment (47-49).

Although the interpretation of our data on coagulation and fibrinolysis may be hampered by the use of an i.v. catheter for blood sampling, we think a few conclusions can be drawn. First, it is obvious that T3.A does not induce activation of coagulation and fibrinolysis. In contrast, T3.G2a induces a rapid activation of fibrinolysis, as evidenced by increased levels of TPA and PAPc at $1 \mathrm{~h}$, followed by a gradual activation of the common pathway of coagulation, as evidenced by slightly increased levels of $F 1+2$ at $6 \mathrm{~h}$. In our opinion, the elevated baseline values of $F 1+2$ in our patients can be ascribed to recent surgery (renal transplantation ). Our results are in agreement with other reports in which activation of fibrinolysis and coagulation have been described after the administration of TNF to healthy humans $(40,50)$, and after the administration of OKT3 to renal transplant recipients (24). Considering the recently described dose-dependent increased incidence of thrombotic complications after OKT3 treatment (26), the absence of effects on coagulation and fibrinolysis may offer an additional advantage to T3.A.

We conclude that an anti-CD3 mAb of the IgA class is better tolerated than an anti-CD3 $\mathrm{mAb}$ of the IgG2a class, causes little or no cytokine release, no complement activation, no activation and degranulation of neutrophil granulocytes and does not affect the procoagulant-fibrinolytic balance. The immunosuppressive properties of T3.A therefore, deserve further investigation.

\section{Acknowledgments}

We wish to thank Drs. C. E. Hack and L. A. M. Frenken for their help in the performance of various assays. Drs. L. A. Aarden and M. Levi for critically reading the manuscript and J. M. Cloos for secretarial assistance.
This work was supported by the Dutch Kidney Foundation Grant C88-775.

\section{References}

1. Parlevliet K. J., and P. T. A. Schellekens. 1992. Monoclonal antibodies in renal transplantation: a review. Transpl. Int. 5:234-246.

2. Todd, P. A., and R. N. Brogden. 1989. Muromonab CD3. A review of its pharmacology and therapeutic potential. Drugs. 37:871-899.

3. Ortho Multicenter Transplant Group. 1985. A randomized clinical trial of OKT3 monoclonal antibody for acute rejection of cadaveric renal transplants. Ortho Multicenter Transplant Study Group. N. Engl. J. Med. 313:337-342.

4. Vigeral, P., N. Chkoff, L. Chatenoud, H. Campos, M. Lacombe, D. Droz, G. Goldstein, J. F. Bach, and H. Kreis. 1986. Prophylactic use of OKT3 monoclonal antibody in cadaver kidney recipients. Utilization of OKT3 as the sole immunosuppressive agent. Transplantation (Baltimore). 41:730-733.

5. Thistlethwaite, J. R., J. K. Stuart, J. T. Mayes, A. O. Gabor, S. Woodle, M. R. Buckingham, and F. P. Stuart. 1988. Monitoring and complications of monoclonal therapy. Am. J. Kidney Dis. 11:112-119.

6. Chatenoud, L., C. Ferran, A. Reuter, C. Legendre, Y. Gevaert, H. Kreis, P. Franchimont, and J. F. Bach. 1989. Systemic reaction to the anti-T-cell monoclonal antibody OKT3 in relation to serum levels of tumor necrosis factor and interferon-gamma. N. Engl. J. Med. 320:1420-1421.

7. Abramowicz, D., L. Schandene, M. Goldman, A. Crusiaux, P. Vereerstraeten, L. De Pauw, J. Wybran, P. Kinnaert, E. Dupont, and C. Toussaint. 1989. Release of tumor necrosis factor, interleukin-2, and gamma-interferon in serum after injection of OKT3 monoclonal antibody in kidney transplant recipients. Transplantation (Baltimore). 47:606-608.

8. Chatenoud, L., C. Ferran, C. Legendre, I. Thouard, S. Merite, A. Reuter, Y. Gevaert, H. Kreis, P. Franchimont, and J. F. Bach. 1990. In vivo cell activation following OKT3 administration. Systemic cytokine release and modulation by corticosteroids. Transplantation (Baltimore). 49:697-702.

9. Bloemena, E., I. J. M. ten Berge, J. Surachno, and J. M. Wilmink. 1990 Kinetics of interleukin 6 during OKT3 treatment in renal allograft recipients. Transplantation (Baltimore). 50:330-331.

10. Ferran, C., K. Sheehan, M. Dy, R. Schreiber, S. Merite, P. Landais, L. H. Noel, G. Grau, J. Bluestone, and J. F. Bach. 1990. Cytokine-related syndrome following injection of anti-CD3 monoclonal antibody: further evidence for transient in vivo T cell activation. Eur. J. Immunol. 20:509-515.

11. Gaston, R. S., M. H. Deierhoi, T. Patterson, E. Prasthofer, B. A. Julian, W. H. Barber, D. A. Laskou, A. G. Diethelm, and J. J. Curtis. 1991. OKT3 first-dose reaction: association with $\mathrm{T}$ cell subsets and cytokine release. Kidney Int. 39:141-148.

12. Ferran, C., K. Sheehan, R. Schreiber, J. F. Bach, and L. Chatenoud. 1991 Anti-TNF abrogates the cytokine-related anti-CD3 induced syndrome. Transplant. Proc. 23:849-850.

13. Charpentier B., C. Hiesse, O. Lantz, C. Ferran, S. Stephens, D. O’Shaugnessy, M. Bodmer, G. Benoit, J-F. Bach, and L. Chatenoud. 1992. Evidence that antihuman tumor necrosis factor monoclonal antibody prevents OKT3-induced acute syndrome. Transplantation (Baltimore). 54:997-1002.

14. Palacios, R. 1985. Mechanisms by which accessory cells contribute in growth of resting $\mathrm{T}$ lymphocytes initiated by OKT3 antibody. Eur. J. Immunol. 15:645-651.

15. Hirsch, R., R. E. Gress, D. H. Pluznik, M. Eckhaus, and J. A. Bluestone. 1989. Effects of in vivo administration of anti-CD3 monoclonal antibody on $T$ cell function in mice. II. In vivo activation of T cells. J. Immunol. 142:737-743.

16. Tax, W. J., F. F. Hermes, R. W. Willems, P. J. Capel, and R. A. Koene. 1984. Fc receptors for mouse IgG1 on human monocytes: polymorphism and role in antibody-induced T cell proliferation. J. Immunol. 133:1185-1189.

17. Debets, J. M., C. J. van der Linden, I. E. Dieteren, J. F. Leeuwenberg, and W. A. Buurman. 1988. Fc-receptor cross-linking induces rapid secretion of tumor necrosis factor (cachectin) by human peripheral blood monocytes. J. Immunol. 141:1197-1201.

18. Kurrle, R., S. Seyfert, A. Trautwein, and F. R. Seiler. 1986. T cell activation by CD3 antibodies. In Leukocyte Typing II, Vol I: Human T-Lymphocytes. E. L. Reinherz, B. F. Haynes, L. M. Nadler, and I. D. Bernstein, editors. Springer, Berlin, Heidelberg, New York. 137-145.

19. Hoffman, T., A. K. Tripathi, Y. L. Lee, E. Bonvini, and B. Golding. 1992. Inflammatory mediator release from human monocytes via immobilized Fc receptors. Transplantation (Baltimore). 54:343-346.

20. Frenken, L. A. M., R. A. P. Koene, and W. J. M. Tax. 1991. The role of antibody isotype in IFN-gamma and IL-2 production during anti-CD3-induced T cell proliferation. Transplantation (Baltimore). 51:881-887.

21. Hirsch, R., J. A. Bluestone, L. DeNenno, and R. E. Gress. 1990. Anti-CD3 $F\left(a b^{\prime}\right) 2$ fragments are immunosuppressive in vivo without evoking either the strong humoral response or morbidity associated with whole mAb. Transplantation (Baltimore). 49:1117-1123. 
22. Parlevliet, K. J., M. Jonker, R. J. M. ten Berge, R. A. W. Van Lier, J. M. Wilmink, P. F. W. Strengers, L. A. Aarden, and P. Th. A. Schellekens. 1990. Anti-CD3 murine monoclonal isotype switch variants tested for toxicity and immunologic monitoring in four chimpanzees. Transplantation (Baltimore). 49:889-892.

23. Raasveld M. H. M., F. J. Bemelman, P. T. A. Schellekens, F. N. J. van Diepen, A. van Dongen, E. A. van Royen, C. E. Hack, and I. J. M. ten Berge. 1993. Complement activation during OKT3 treatment: a possible explanation for respiratory side effects. Kidney Int. 43:1140-1149.

24. Raasveld, M. H. M., C. E. Hack, and R. J. M. ten Berge. 1992. Activation of coagulation and fibrinolysis following OKT3 administration to renal transplant recipients: Association with distinct mediators. Thromb. Haemostasis. 68:264-267.

25. Raasveld, M. H. M., S. Surachno, C. E. Hack, and R. J. M. ten Berge 1992. Thromboembolic complications and dose of monoclonal OKT3 antibody 26. Lancet. 339:1363-1364.

26. Abramowicz, D., O. Pradier, A. Marchant, S. Florquin, L. De Pauw, P. Vereerstraeten, P. Kinnaert, J. L. Vanherweghem, and M. Goldman. 1992. Induction of thromboses within renal grafts by high-dose prophylactic OKT3. Lancet. 339:777-778.

27. Lier van, R. A., J. H. Boot, E. R. de Groot, and L. A. Aarden. 1987 Induction of $\mathrm{T}$ cell proliferation with anti-CD3 switch-variant monoclonal antibodies: effects of heavy chain isotype in monocyte-dependent systems. Eur. $J$. Immunol. 17:1599-1604.

28. Boot, J. H., M. E. Geerts, E. R. de Groot, and L. A. Aarden. 1988. Murine monoclonal isotype switch variants. Detection with rat monoclonal antibodies in ELISA and isolation by sequential sublining. J. Immunol. Methods. 106:195202.

29. Roosnek, E. E., R. A. W. Van Lier, and L. A. Aarden. 1987. Two monoclonal anti-CD3 antibodies can induce different events in human $\mathrm{T}$ lymphocyte activation. Eur. J. Immunol. 17:1507-1510.

30. Helle, M., L. Boeye, E. de Groot, A. de Vos, and L. A. Aarden. 1991. Sensitive ELISA for interleukin-6; detection of IL-6 in biological fluids: synovial fluids and sera. J. Immunol. Methods. 138:47-52.

31. Hack, C. E., J. Paardekooper, A. J. Eerenberg, G. O. Navis, M. W. Nijsten, L. G. Thijs, and J. H. Nuijens. 1988. A modified competitive inhibition radioimmunoassay for the detection of C3a. Use of 125I-C3 instead of 125I-C3a. J. Immunol. Methods. 107:77-82.

32. Wolbink, G. J., J. Bollen, J. W. Baars, R. J. M. ten Berge, A. J. G. Swaak, J. Paardekooper, and C. E. Hack. 1993. Application of a monoclonal antibody against a neoepitope on activated C4 in an ELISA for the quantification of complement activation via the classical pathway. J. Immunol. Methods. 163:67-76.

33. Nuyens, J. H., J. J. Abbink, Y. T. Wachtfogel, R. W. Colman, A. J. M. Eerenberg, D. Dors, A. J. M. Kamp, R. J. M. Strack van Schijndel, L. G. Thijs, and C. E. Hack. 1992. Plasma elastase alphal-antitrypsin and lactoferrin in sepsis: evidence for neutrophils as mediators in fatal sepsis. J. Lab. Clin. Med. 119:159-168.

34. Levi, M., J. P. de Boer, D. Roem, J. W. ten Cate, and C. E. Hack. 1992. Plasminogen Activation In Vivo upon Intravenous Infusion of DDAVP. Thromb. Haemostasis. 67:111-116.

35. Chatenoud, L., M. F. Baudrihaye, N. Chkoff, H. Kreis, G. Goldstein, and J. F. Bach. 1986. Restriction of the human in vivo immune response against the mouse monoclonal antibody OKT3. J. Immunol. 137:830-838.

36. Alegre, M. L., P. Vandenabeele, M. Depierreux, S. Florquin, M. Des-
chodt-Lanckman, V. Flamand, M. Moser, L. Oberdan, J. Urbain, W. Fiers, and M. Goldman. 1991. Cytokine release syndrome induced by the $145-2 \mathrm{cll}$ antiCD3 monoclonal antibody in mice: prevention by high doses of methylprednisolone. J. Immunol. 146:1184-1187.

37. Ferran, C., M. Dy, S. Merite, K. Sheehan, R. Schreiber, F. Leboulenger, P. Landais, J. Bluestone, J. F. Bach, and L. Chatenoud. 1990. Reduction of morbidity and cytokine release in anti-CD3 moab-treated mice by corticosteroids. Transplantation (Baltimore). 50:642-648.

38. Goldman, M., D. Abramowicz, L. De Pauw, M. L. Alegre, I. Widera, P. Vereerstraeten, and Kinnaert. 1989. OKT3-induced cytokine release attenuation by high-dose methylprednisolone letter. Lancet. 2:802-803.

39. Chatenoud, L., C. Legendre, F. Ferran, J-F. Bach, and H. Kreis. 1991. Corticosteroid inhibition of the OKT3-induced cytokine-related syndrome-dosage and kinetics prerequisites. Transplantation (Baltimore). 51:334-338.

40. Woodle, E. S., J. R. Thistlethwaite, I. A. Ghobrial, L. K. Joliffe, F. P. Stuart, and J. A. Bluestone. 1991. OKT3 F(ab')2 fragments-retention of the immunosuppressive properties of whole antibody with marked reduction in $\mathrm{T}$ cell activation and lymphokine release. Transplantation (Baltimore). 52:354 360 .

41. Poll van der T., H. R. Buller, H. ten Cate, C. H. Wortel, K. A. Bauer, S. J. van Deventer, C. E. Hack, H. P. Sauerwein, R. D. Rosenberg, and J. W. ten Cate 1990. Activation of coagulation after administration of tumor necrosis factor to normal subjects. $N$. Engl. J. Med. 322:1622-1627.

42. Koivuranta, V., P. Vaara, D. Banda, and I. M. Goldstein. 1987. Bacteriallipopolysaccharide-induced release of lactoferrin from human polymorpho-nuclear leukocytes: role of monocyte-derived tumor necrosis factor alpha. Infect. Immun. 55:2956.

43. Richter, J., T. Andersson, and I. Olsson. 1989. Effect of tumor necrosis factor and granulocyte/macrophage colony-stimulating factor on neutrophil degranulation. J. Immunol. 142:3199-3207.

44. van Deventer, S. J. H., C. E. Hack, G. J. Wolbink, H. J. Voerman, R. J. M Strack van Schijndel, J. W. ten Cate, and L. G. Thijs. 1991. Endotoxin-induced neutrophil activation. The role of complement revisited. In Bacterial Endotoxins: Cytokine Mediators and New Therapies for Sepsis. J. Levin, A. Sturk, and J. W. ten Cate, editors. John Wiley \& Sons, New York. 101 pp.

45. Poll van der T., S. J. H. van Deventer, C. E. Hack, G. J. Wolbink, L. A. Aarden, H. R. Buller, and J. W. ten Cate. 1992. Effects on leukocytes after injection of tumor necrosis factor into healthy humans. Blood. 79:693-698.

46. Berge, R. J. M. ten, H. P. Sauerwein, S-L. Yong, and P. Th. A. Schellekens. 1984. Administration of prednisolone in vivo affects the ratio of OKT4/OKT8 and the LDH isoenzyme pattern of human T lymphocytes. Clin. Immunol. Immunopathol. 30:91-102.

47. Chatenoud, L., M. F. Baudrihaye, H. Kreis, G. Goldstein, J. Schindler, and J. F. Bach. 1982. Human in vivo antigenic modulation induced by the anti-T cell OKT3 monoclonal antibody. Eur. J. Immunol. 12:979-982.

48. Gebel, H. M., L. L. Lebeck, S. C. Jensik, A. L. Landay, and R. A. Bray. 1989. Discordant expression of CD3 and T-cell receptor antigens on lymphocytes from patients treated with OKT3. Transplant. Proc. 21:1745-1746.

49. Gebel, H. M., L. K. Lebeck, S. C. Jensik, K. Webster, and R. A. Bray. 1989. T cells from patients successfully treated with OKT3 do not react with the $T$ cell receptor antibody. Hum. Immunol. 26:123-129.

50. Poll van der T., M. Levi, H. R. Buller, S. J. van Deventer, J. P. de Boer, C. E. Hack, and J. W. ten Cate. 1991. Fibrinolytic response to tumor necrosis factor in healthy subjects. J. Exp. Med. 174:729-732. 